\title{
Differences of Physique and Physical Fitness among Male South Korean Elite National Track and Field Athletes
}

\author{
Sung, Bong-ju*, Ko, Byoung-goo \\ Korea Institute of Sport Science, Korea
}

Copyright $@ 2017$ by authors, all rights reserved. Authors agree that this article remains permanently open access under the terms of the Creative Commons Attribution License 4.0 International License

\begin{abstract}
The aim of this study was to provide a detailed comparison of physique and physical fitness differences among Track and Field groups. The male athletes participating in this study consisted only of South Korean national track and field athletes. The Korean national athletes were divided into four groups (long-distance runner, sprinter, jumper, thrower). The long-distance runner group $(n=7)$ consisted of three male marathoners and four male race walkers. The sprinter group $(n=7)$ consisted of five male $100 \mathrm{~m}$ athletes and two male hurdlers. The jumper group $(n=7)$ consisted of 2 male high jumpers, 2 male long

97kg, grip strength: $81 \mathrm{~kg}$ ) was superior to the other three groups in muscular strength and was heavier than the other groups. Korean national track \& field athletes showed the characteristics of cardiovascular endurance, muscular strength, and power in a detailed analysis of items. No differences were found in muscular endurance, flexibility, and agility. Differences in physique and physical fitness among detail event groups of Korean national athletes were in accordance with previous studies. In future studies, the sample size should be increased to improve the reliability and validity of the study results.
\end{abstract} jumpers, and 3 male pole vault athletes. The thrower group $(n=8)$ consisted of 2 male shot put athletes, two male javelin throwers, 2 male discus throwers and 2 male hammer throwers. This study was designed to investigate the effects of physique (height, weight), muscular strength (grip strength), muscular endurance (push-ups, sit-ups), agility (side step), power (vertical jump), cardiopulmonary endurance (maximal oxygen uptake, Anaerobic Threshold $\% \mathrm{VO}_{2} \max$, rest heart rate), and flexibility (sit and reach). A one-way ANOVA was performed for the mean difference test among track and field athlete groups. A post hoc test method was conducted through the Scheffe Test. The results are as follows. The thrower athlete group showed significantly better results in weight, muscular strength (grip power) than the sprinter athlete group, long-distance runner group and the jumper athlete group. The long-distance runner group showed significantly better result in $\mathrm{VO}_{2} \max$ and AT (Anaerobic Threshold) than the sprinter group, thrower group and the jumper group. The sprinter group showed significantly better results in power (vertical jump) than the other three groups. There was no significant difference among the groups in the results for muscular endurance (push-up, sit-up), flexibility (sit and reach) and agility (side steps). In conclusion, the South Korean national long-distance runner group $\left(\mathrm{VO}_{2} \max\right.$ : $72.6 \mathrm{ml} / \mathrm{kg} / \mathrm{min}, \mathrm{ATVO}_{2}$ max: $54 \mathrm{ml} / \mathrm{kg} / \mathrm{min}$ ) was superior to the other three groups in cardiovascular endurance. The sprinter's group (vertical jump: $63.1 \mathrm{~cm}$ ) was superior to the other three groups in power. The thrower group (weight:
Keywords Korean National Athlete, Physique and Fitness, Long-distance Runner, Sprinter, Jumper, Thrower, Track and Field

\section{Introduction}

The types of track and field athletics can largely be divided into track field and road events, and, in a detailed division, it can be thoroughly divided into racing, jumping, throwing, combined events and race walking.

When looking at the most important physical fitness factors in the track and field athletics group, power, anaerobic endurance and agility is the most important in the sprinter group. Aerobic endurance is the most important in long distance runners and the marathoner group. Strength, power, and coordination are important in the thrower athlete group. Muscular strength, power, flexibility and coordination have a significant effect in the jumper group [11].

The importance of physical fitness is emphasized because it is an important factor in performance, which is a constituent of physical fitness [22. 23].

Maximal oxygen uptake, which is one of the main factors of cardiopulmonary endurance evaluation, refers to the maximum amount of oxygen per unit time that the human body can take during exercise. This means that the body's 
main energy source, oxygen, is supplied to the muscles to remove the waste resulting from long-term exercise [24].

As the maximal oxygen uptake occupies a high range of genetic properties, it is not expected to increase by more than $10-20 \%$ through regular training [25]. The maximal oxygen uptake was not appropriate for the maximal exercise capacity assessment [26], and an anaerobic threshold was also used as an index of endurance exercise capacity [10].

It is important to identify the major fitness factors that affect the performance of each sport in order to obtain excellent records, because physical fitness factors are more influenced by physical factors than technique factor [10].

Previous studies have shown that Korean high school sprinters are superior to other type of athletes in power and muscular endurance, middle-long distance runners were superior to other types of athletes in cardiovascular endurance and muscular endurance, and jumpers were superior to other types of athletes in muscular strength, agility, power and balance. High school throwers were superior to other type of athletes in muscular strength, agility and power [1]. As well, South Korean elite national track-field fitness research is sparse and therefore, the aim of this study was to evaluate the physical characteristics of the South Korean national track and field team in each event (sprinter, marathoner, jumper and thrower group).

The purpose of this study is to compare physical physique and physical fitness differences by detail group of Track \& Field

\section{Materials and Methods}

\subsection{Subject}

The subjects $(\mathrm{n}=25)$ were divided into four groups $(7$ Sprinters, 7 long-distance runners, 7 jumpers, 4 throwers). The male athletes participating in this study consisted only of South Korean national track and field athletes. The long-distance runner group $(\mathrm{n}=7)$ consisted of three male marathoners and four male race walkers. The sprinters group $(\mathrm{n}=7)$ consisted of five male $100 \mathrm{~m}$ sprinters and two male hurdlers. The jumper group $(\mathrm{n}=7)$ consisted of two male high jumpers, two male long jumpers, and three male pole vault athletes. The thrower group $(n=4)$ consisted of one male decathlon athlete, two male javelin throwers and one male hammer thrower.

The focus of interest concerned the physique and fitness difference between the groups. The evaluated items consisted of physique (height, weight), muscular endurance (push-ups, sit-ups), muscular strength (grip), flexibility (sit and reach), agility (side-step), power (vertical jump), and cardiovascular endurance $\left(\mathrm{VO}_{2} \max , \mathrm{ATVO}_{2} \mathrm{max}\right)$.

The physical characteristics of participants are shown in Table 1.
Table 1. Physical characteristics of participants

\begin{tabular}{|c|c|c|c|c|c|}
\hline Group & $\begin{array}{c}\text { Height } \\
(\mathrm{cm})\end{array}$ & $\begin{array}{c}\text { Weight } \\
(\mathrm{kg})\end{array}$ & $\begin{array}{c}\text { Body fat } \\
(\%)\end{array}$ & BMI & Age (yrs) \\
\hline $\begin{array}{c}\text { Long-distance } \\
\text { runner } \\
(\mathrm{n}=7)\end{array}$ & $\begin{array}{c}177.7 \\
\pm 4.07\end{array}$ & $\begin{array}{c}66.4 \\
\pm 4.46\end{array}$ & $\begin{array}{c}16.1 \\
\pm 1.80\end{array}$ & $\begin{array}{c}21.0 \\
\pm 0.96\end{array}$ & $\begin{array}{c}26.6 \\
\pm 4.12\end{array}$ \\
\hline $\begin{array}{c}\text { Sprinter } \\
\text { (n=7) }\end{array}$ & 184.3 & 77.3 & 15.2 & 22.8 & 23.9 \\
\hline 5.85 & \pm 5.92 & \pm 4.11 & \pm 0.96 & \pm 5.4 \\
\hline $\begin{array}{c}\text { Jumper } \\
\text { (n=7) }\end{array}$ & 185.0 & 73.8 & 14.2 & 21.6 & 23.7 \\
\hline $\begin{array}{c}\text { Thrower } \\
(\mathrm{n}=8)\end{array}$ & 181.8 & \pm 4.21 & \pm 3.03 & \pm 1.18 & \pm 4.86 \\
\hline
\end{tabular}

Values are Mean \pm SD

\subsection{Performance Tests}

\section{Body Composition}

Body composition and body fat mass were measured using Inbody 3.0 (Biospace, Korea), an impedance measuring instrument.

\section{Muscular Strength}

Muscular strength was measured using a back muscular strength machine (TKK-1270A, TAKEI, Japan) and grip strength machine (TKK-1270, TAKEI, Japan). Muscular Strength was measured twice and peak value was recorded in $0.1 \mathrm{~kg}$ units.

\section{Muscular Endurance}

Muscular endurance was evaluated by push-ups and sit-ups. Muscular endurance (sit-ups) was recorded during 60 seconds.

\section{Flexibility}

Flexibility was measured using sit and reach test machine (WT-PAPS-007, WELLTEK, Korea). The test is performed by sitting with the feet barefoot straight against the vertical plane of the measuring instrument. Then with both hands gathered and knees fully upright, the upper body bends forward and pushes the meter as far forward as possible. The point where the fingertip stops at about 2 seconds was measured and the high value was recorded in $0.1 \mathrm{~cm}$ units.

\section{Power}

The power factor was measured through vertical jump. The test is performed by arranging the feet at a distance of $20 \mathrm{~cm}$ from the wall where the measuring board is installed, and raising the hand alongside the wall. The knee is bent at the spot and raised as high as possible and the plate is measured with the fingertips. Measure the distance between the height of the fingertip at the time of the jump and the distance between the hands stretched prior to the jump. Two measurements were made and high values were recorded in $0.1 \mathrm{~cm}$ units. 
Agility

Agility was measured through a side step test. The center line is centered on the floor with parallel lines spaced $120 \mathrm{~cm}$ apart from each other. With the start signal, both feet should be moved outward beyond the line, then returned to the center, and then moved back to the opposite direction. The number of line passes over 20 seconds was measured. Measurements were taken twice, and the highest number of measurement results was recorded.

\section{Cardiovascular Endurance}

For the measurement of cardiopulmonary function, a graded exercise test (GXT) method was chosen. Using the KISS protocol (Korea Institute of Sport Science Protocol, Korea) developed by the Korea Institute of Sport Science, the slope was fixed (6\% for male, $5 \%$ for female) and the 1-phase exercise was conducted for 2 minutes at $2 \mathrm{mph}$ with a respiratory gas analyzer (Quark4b2, Cosmed Co, Italy) After the exercise, the speed was increased by $0.7-1.17 \mathrm{mph}$ every 2 minutes and the exercise was terminated when the exercise could not be continued by the athlete. $\mathrm{VO}_{2} \max$, anaerobic threshold percentage (AT\% $\mathrm{VO}_{2} \max$ ) and resting heart rate were selected as the main variables in this study.

\subsection{Statistical Analysis}

All statistical analyses were conducted using SPSS Statistics 20 (IBM SPSS, Inc., USA). The mean and standard deviation of each item (10 items) were calculated. A one-way ANOVA was performed for the mean difference test among the track and field athlete groups. When the statistical significance level was confirmed, a Scheffe Test post test was conducted. The reliability of the statistical significance level was $95 \%$.

\section{Result}

All sources cited in the text must appear in the reference list, and all items in the reference list must be cited in the text. With the numerical system, references are arranged in the reference list so that they match the order in which they are cited in the text.

\subsection{Physique (Height and Weight)}

The average of the height and the result of the calculation are shown in Table 2.

As shown in Table 2, height $(\mathrm{cm})$ was no statistically significant difference among the 4 exercise groups. .

The average of the body weight and the result of the calculation are shown in Table 3.

As shown in Table 3 , the body weight $(\mathrm{kg})$ was statistically significant $(\mathrm{p}<0.001)$ according to the track and field group. The thrower group was significantly higher than long distance (marathon), sprinter and jumping athlete groups $(\mathrm{p}=0.0000)$.

Table 2. Mean values and statistical results of the height

\begin{tabular}{|c|c|c|c|c|c|c|c|}
\hline $\begin{array}{c}\text { Dependent } \\
\text { variable }\end{array}$ & Group & Mean & $\mathrm{SD}$ & Sample size & $\mathrm{F}$ & $\mathrm{p}$-value & Scheffe Test \\
\hline \multirow{3}{*}{ Height (cm) } & 1 & 177.7 & 4.07 & 7 & \multirow{3}{*}{$3338 *$} & \multirow{3}{*}{0.035} & \multirow{3}{*}{ NS } \\
\hline & 3 & 185.0 & 4.32 & 7 & & & \\
\hline & Total & 183.1 & 5.86 & 29 & & & \\
\hline
\end{tabular}

Values are Mean $\pm \mathrm{SD}$; 1: long-distance runner group, 2: sprinter group, 3: jumper group, 4: thrower group $* \mathrm{p}<0.05 \quad \mathrm{a}: 1, \mathrm{~b}: 2, \mathrm{c}: 3, \mathrm{~d}: 4$

Table 3. Mean values and statistical results of the body weight (kg)

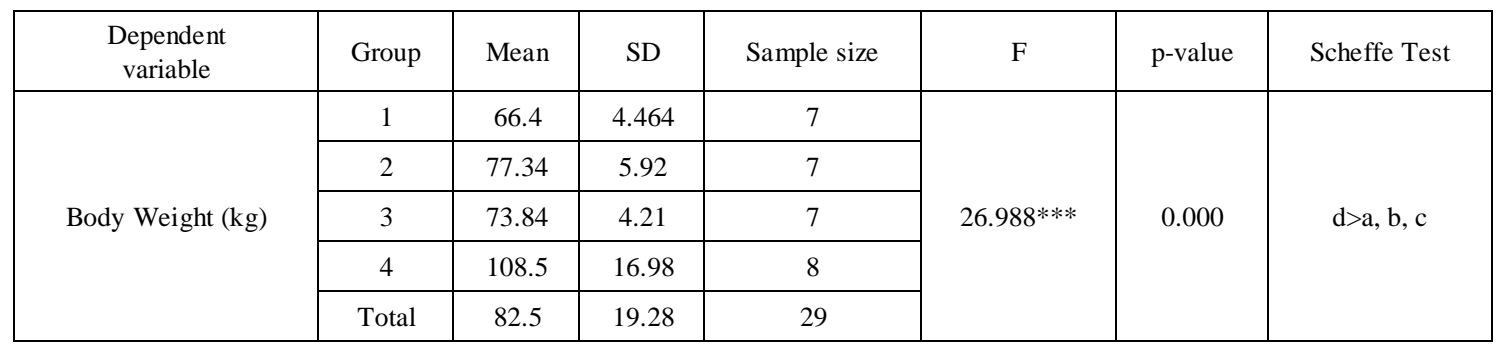

Values are Mean \pm SD, 1: long-distance runner group, 2: sprinter group, 3: jumper group, 4: thrower group

$* * *$ p $<0.001$ a:1, b:2, c:3, d:4 
Table 4. Mean values and statistical results of grip strength $(\mathrm{kg})$

\begin{tabular}{|c|c|c|c|c|c|c|c|}
\hline $\begin{array}{l}\text { Dependent } \\
\text { variable }\end{array}$ & Group & Mean & SD & Sample size & $\mathrm{F}$ & p-value & Scheffe Test \\
\hline \multirow{5}{*}{ Grip strength (kg) } & 1 & 51.8 & 8.56 & 7 & \multirow{5}{*}{$13.380^{* * *}$} & \multirow{5}{*}{0.000} & \multirow{5}{*}{$\begin{array}{l}\mathrm{d}>\mathrm{a} \\
\mathrm{d}>\mathrm{b} \\
\mathrm{d}>\mathrm{c}\end{array}$} \\
\hline & 2 & 61.0 & 8.14 & 7 & & & \\
\hline & 3 & 59.8 & 8.36 & 5 & & & \\
\hline & 4 & 77.8 & 7.95 & 8 & & & \\
\hline & Total & 63.4 & 12.83 & 27 & & & \\
\hline
\end{tabular}

Values are Mean $\pm \mathrm{SD}, 1$ : long-distance runner group, 2: sprinter group, 3: jumper group, 4: thrower group *** $\mathrm{p}<0.001$ a:1, b:2, c:3, d:4

Table 5. Mean values and statistical results of push-ups

\begin{tabular}{|c|c|c|c|c|c|c|c|}
\hline $\begin{array}{c}\text { Dependent } \\
\text { variable }\end{array}$ & Group & Mean & SD & Sample size & $\mathrm{F}$ & $\mathrm{p}$-value & Scheffe Test \\
\hline \multirow{5}{*}{ Push-ups (beats/min) } & 1 & 51.9 & 12.29 & 7 & \multirow{5}{*}{1.578} & \multirow{5}{*}{0.223} & \multirow{5}{*}{ NS } \\
\hline & 2 & 50.2 & 8.95 & 6 & & & \\
\hline & 3 & 47.6 & 4.51 & 5 & & & \\
\hline & 4 & 41.6 & 10.1 & 8 & & & \\
\hline & Total & 47.5 & 10.1 & 26 & & & \\
\hline
\end{tabular}

Values are Mean $\pm \mathrm{SD}, 1$ : long-distance runner group, 2: sprinter group, 3: jumper group, 4: thrower group a:1, b:2, c:3, d:4

Table 6. Mean values and statistical results of sit-ups (beats/min)

\begin{tabular}{|c|c|c|c|c|c|c|c|}
\hline $\begin{array}{c}\text { Dependent } \\
\text { variable }\end{array}$ & Group & Mean & $\mathrm{SD}$ & Sample size & $\mathrm{F}$ & $\mathrm{p}$-value & Scheffe Test \\
\hline \multirow{5}{*}{ Sit-ups (beats/min) } & 1 & 57.4 & 8.66 & 7 & \multirow{5}{*}{3.076} & \multirow{5}{*}{0.048} & \multirow{5}{*}{ NS } \\
\hline & 2 & 56.4 & 7.32 & 7 & & & \\
\hline & 3 & 60.0 & 2.55 & 5 & & & \\
\hline & 4 & 48.4 & 8.68 & 8 & & & \\
\hline & Total & 55.0 & 8.45 & 27 & & & \\
\hline
\end{tabular}

Values are Mean $\pm S D, 1$ : long-distance runner group, 2: sprinter group, 3: jumper group, 4: thrower group a:1, b:2, c:3, d:4

\subsection{Muscular Strength}

To compare muscular strength, the difference of grip strength was compared in the 4 athlete groups.

The average of the grip strength and the results of the calculation are shown in Table 4.

The thrower group had a significantly higher grip strength than long distance, sprinter, and jumpers groups ( $\mathrm{p}$ $<0.001$ ). As a result, throwing athletes were the best in muscular strength (grip strength).

\subsection{Muscular Endurance}

To determine the difference of muscular endurance, push-ups and sit-ups were selected. The mean value and statistical results of push-ups (beats) for each group are show in Table 5.

There was no statistically significant difference between the exercise groups for push-ups (beats).

The mean value and statistical results of sit-ups (beate/min) for each group are shown in Table 6.

There was no statistically significant difference between the exercise groups for sit-ups (beats/min).

As a result, muscle endurance was not significantly different among the four athlete groups.

\subsection{Flexibility}

A sit and reach test was selected to compare the flexibility of the four track and field athlete groups.

The mean values and the statistical results of the sit and reach test $(\mathrm{cm})$ are shown in Table 7. 
Table 7. Mean values and statistical results of sit and reach (cm)

\begin{tabular}{|c|c|c|c|c|c|c|c|}
\hline $\begin{array}{c}\text { Dependent } \\
\text { variable }\end{array}$ & Group & Mean & SD & Sample size & $\mathrm{F}$ & $\mathrm{p}$-value & Scheffe Test \\
\hline \multirow{5}{*}{ Sit and reach $(\mathrm{cm})$} & 1 & 16.9 & 7.60 & 7 & \multirow{5}{*}{0.314} & \multirow{5}{*}{0.815} & \multirow{5}{*}{ NS } \\
\hline & 2 & 17.5 & 6.19 & 7 & & & \\
\hline & 3 & 17.9 & 6.72 & 5 & & & \\
\hline & 4 & 15.0 & 3.35 & 8 & & & \\
\hline & Total & 16.6 & 5.79 & 27 & & & \\
\hline
\end{tabular}

Values are Mean $\pm S D, 1$ : long-distance runner group, 2: sprinter group, 3: jumper group, 4: thrower group $\mathrm{a}: 1, \mathrm{~b}: 2, \mathrm{c}: 3, \mathrm{~d}: 4$

Table 8. Mean values and statistical results of side step (beats/20 seconds)

\begin{tabular}{|c|c|c|c|c|c|c|c|}
\hline $\begin{array}{c}\text { Dependent } \\
\text { variable }\end{array}$ & Group & Mean & SD & Sample size & $\mathrm{F}$ & p-value & Scheffe Test \\
\hline \multirow{5}{*}{ side step (beats/20 seconds) } & 1 & 43.0 & 4.44 & 7 & \multirow{5}{*}{1.706} & \multirow{5}{*}{0.195} & \multirow{5}{*}{ NS } \\
\hline & 2 & 45.9 & 5.904 & 7 & & & \\
\hline & 3 & 48.8 & 3.964 & 5 & & & \\
\hline & 4 & 45.6 & 2.43 & 7 & & & \\
\hline & Total & 45.6 & 4.58 & 26 & & & \\
\hline
\end{tabular}

Values are Mean $\pm S D, 1$ : long-distance runner group, 2: sprinter group, 3: jumper group, 4: thrower group a:1, b:2, c:3, d:4

Table 9. Mean values and statistical results of sergent jump (cm)

\begin{tabular}{|c|c|c|c|c|c|c|c|}
\hline $\begin{array}{c}\text { Dependent } \\
\text { variable }\end{array}$ & Group & Mean & SD & Sample size & $\mathrm{F}$ & $\mathrm{p}$-value & Scheffe Test \\
\hline \multirow{5}{*}{ vertical jump (cm) } & 1 & 40.6 & 6.62 & 7 & \multirow{5}{*}{$20.863^{* * *}$} & \multirow{5}{*}{0.000} & \multirow{5}{*}{$\mathrm{b}, \mathrm{c}, \mathrm{d}>\mathrm{a}$} \\
\hline & 2 & 63.1 & 6.28 & 7 & & & \\
\hline & 3 & 57.6 & 7.37 & 5 & & & \\
\hline & 4 & 67.5 & 7.51 & 8 & & & \\
\hline & total & 57.6 & 12.6 & 27 & & & \\
\hline
\end{tabular}

Values are Mean $\pm \mathrm{SD}, 1$ : long-distance runner group, 2: sprinter group, 3: jumper group, 4: thrower group

There was no statistically significant difference in the sit and reach test $(\mathrm{cm})$ among the four track and field groups.

As a result, there was no difference in flexibility among the four track and field athlete groups.

\subsection{Agility}

The side step test (beat/20 seconds) was selected for the comparison of agility among the four athletes groups. The mean values and statistical results of the side steps (beat/20 seconds) and the vertical jump (cm) among the four athlete groups are the shown in Table 8.

There was no statistically significant difference in side steps (beats/20 seconds) among the track and field athlete groups.

\subsection{Power}

The vertical jump (cm) was selected for the comparison of the power difference among the four athlete groups. The mean values and statistical results of the vertical jump (cm) among the four athlete groups are the shown in Table 9.

The long-distance runners group showed a significantly lower vertical jump $(\mathrm{cm})$ than the sprinters, jumpers and throwers group $(\mathrm{p}<.001)$.

As a result, sprinters outperformed long-distance runners, jumpers and throwers in power.

\subsection{Cardiovascular Endurance}

The $\mathrm{VO}_{2} \max (\mathrm{ml} / \mathrm{kg} / \mathrm{min})$, AT (Anaerobic Threshold) and Resting Heart Rate were selected for the comparison of cardiovascular endurance among the four track and field athlete groups. The mean values and statistical results of the $\mathrm{VO}_{2} \max (\mathrm{ml} / \mathrm{kg} / \mathrm{min})$, AT (Anaerobic Threshold) and Resting Heart Rate among the four athlete groups are shown 
in Tables 10, 11, and 12.

The maximal oxygen uptake $(\mathrm{ml} / \mathrm{kg} / \mathrm{min})$ was significantly $(\mathrm{p}<.01)$ higher in the long-distance runner group than the jumper group or thrower group as shown in Table 10. And sprinter and jumper groups were significantly higher than the thrower group in maximal oxygen uptake ( $\mathrm{p}$ $<.0001$ ).

As shown in Table 11, the anaerobic threshold
$\mathrm{AT} \% \mathrm{VO}_{2}$ max was significantly higher in the long-distance runners group than the sprinter and thrower group $(\mathrm{p}<.0001)$. And sprinter group was significantly higher than the thrower group $(\mathrm{p}<.0001)$.

As shown in Table 12, there was no significant difference in the resting heart rate (beats/min) among the four athlete groups.

Table 10. Mean values and statistical results of $\mathrm{VO}_{2} \max (\mathrm{ml} / \mathrm{kg} / \mathrm{min})$

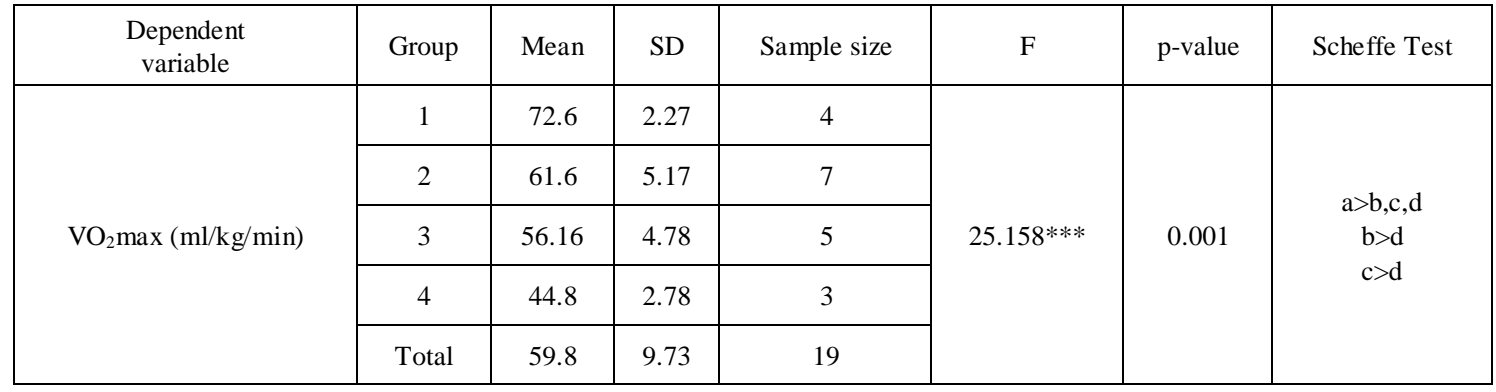

Values are Mean $\pm S D, 1$ : long-distance runner group, 2: sprinter group, 3: jumper group, 4: thrower group $* * * \mathrm{p}<0.001$ a:1, b:2, c:3, d:4

Table 11. Mean values and statistical results of anaerobic Threshold percentage $\mathrm{VO}_{2} \max \left(\mathrm{AT} \% \mathrm{VO}_{2} \max \right)$

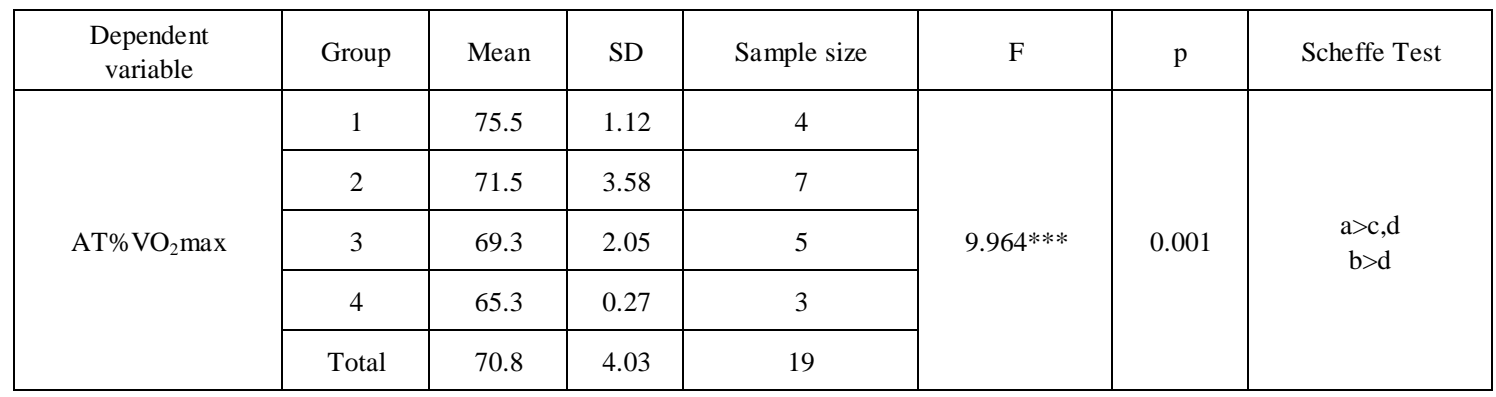

Values are Mean \pm SD, 1: long-distance runner group, 2: sprinter group, 3: jumper group, 4: thrower group $* * * \mathrm{p}<0.001 \mathrm{a}: 1, \mathrm{~b}: 2, \mathrm{c}: 3, \mathrm{~d}: 4$

Table 12. Mean values and statistical results of HRrest (beats/min)

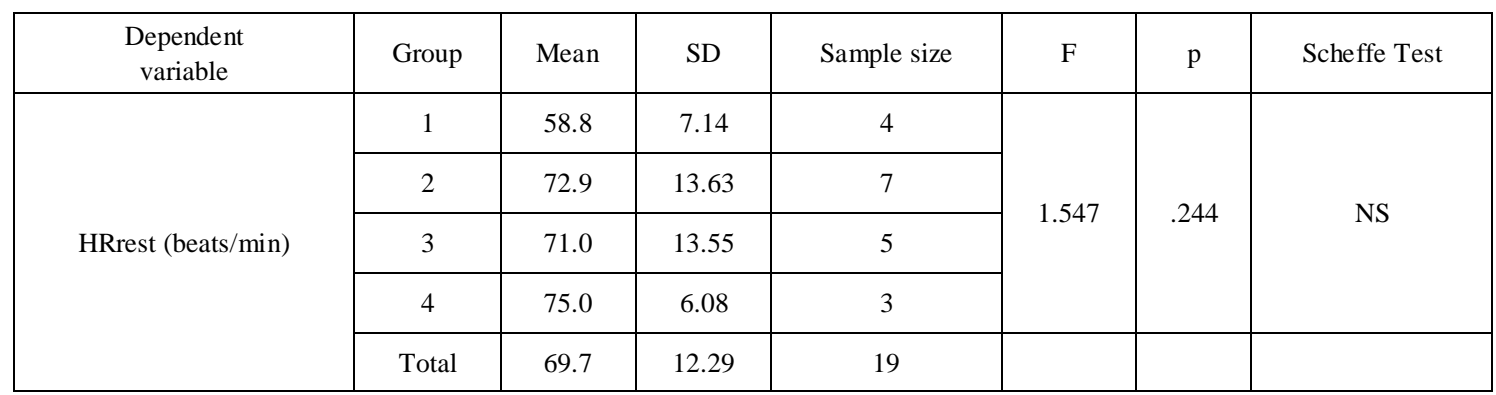

a:1, b:2, c:3, d:4 ; 1: : long-distance runner r group, 2: sprinter group, 3: jumper group, 4: thrower group 


\section{Discussion}

The current study is a research on Korean track and field national players and has its important as an elite athletes study. However its limitation is that the number of samples is small and there is some concern to interpret the results as they are.

The athletic events (track and field) mainly include walking, running, jumping and throwing, and these are the most important and the oldest traditional sports events in human history as the basic movement of all sports. Track and field events (race walking, running, jumping, throwing) are an essential element of exercise for both athletes as well as young people because they play an important role in basic physical fitness and basic functioning at a young age [5]. The muscles have the strongest influence on the performance of elite South Korean high school throwers while cardiovascular endurance and muscular endurance have the strongest influence on the endurance of middle-long distance runners [1].

Athletes differ in body composition [6]. The body fat percentage of the South Korean National athletes participating in this study was higher than the general level. The percentage of body fat of the male marathon athletes group, in particular, was $16 \%$, which is because the measurement occurred after a 1-2 month rest period in preparation for the competitive season. For reference, the body fat percentage of Korean male national marathon runners was $7.3 \%$ in 2010 , and that of female marathon national runners was $13.8 \%$ in 2010 . The body fat percentage of male national runners in 2016 was $10.4 \%$.

Body weight, body mass, Body mass index(BMI), and body fat percentage were significantly higher in sprinter group and thrower group than in long-distance runner group[27]. This shows that body size and body composition level reflect detail sports event.

As a result of comparing the difference of physique between the finalists of the track and field World Championships in 2005 and South Korean national athletes, the difference in physique was not significant in most sports event except for the throwing athletes. In some cases (male $100 \mathrm{~m}$, male $10,000 \mathrm{~m}$, male pole vault, female $100 \mathrm{~m}$, female $5,000 \mathrm{~m}$, female $10,000 \mathrm{~m}$ ), South Korean National track and field athletes were taller than average world champions finalists. Therefore, in order for Korean athletes to compete with world athletes, more attention should be paid to training professional physical fitness rather than physical physique [9].

In this study, sprinters and jumpers were significantly higher than the marathoner group. The athletes in the jumper group must be tall with a high center of gravity, and long in the lower legs [11]. It is not necessarily advantageous to have greater height and weight in order to achieve a rapid speed. For greater speed, it is more important to have a more balanced muscular type body than to have greater height. The average height of the male athletes who entered the $100 \mathrm{~m}$ final of the 2009 World Athletics Championships was $185.4 \mathrm{~cm}$ and the South national sprinter was $182.1 \mathrm{~cm} \mathrm{[12].} \mathrm{As} \mathrm{a} \mathrm{reference,} \mathrm{the}$ height and weight of the South Korean national male thrower groups are $183.1 \mathrm{~cm}, 92.2 \mathrm{~kg}$ in javelin, $187.1 \mathrm{~cm}, 119.2 \mathrm{~kg}$ in shot put, $184.3 \mathrm{~cm}, 91.8 \mathrm{~kg}$ in discus, and $185 \mathrm{~cm}, 117.6 \mathrm{~kg}$ in the hammer [13].

As such, the trends of Korean national runners have already become world class. In order to compete with world-class athletes, Korean athletes have to increase their physical strength, i.e., the size of the body's engine. Therefore, it is now necessary to apply effective training methods in the field to improve professional fitness. Muscle size should be increased first to gain muscle strength. Growing muscle size means increasing weight. In athletics, the thrower group needs the most power. In sprint and jump event, muscular strength is directly related to performance. In particular, since the femur and the lower limbs operate together, stronger force is generated on the thigh. However the ankle plays the finishing role in running more flexibly by receiving the force of the femur[28]. Physique is highly correlated with the physical characteristics suitable for the specific sports events and the development of the athletic functions required in each sport. Therefore it is very likely to be a key factor in determining the level of performance depending on the type of event [7].

In this study, the throwers were significantly heavier than the marathoner, sprinter, and jumper groups. This is because important physical strength factors of throwers are power, equilibrium, and flexibility, among which the power is the most important determining factor [11]. Because power is based on strong muscles, the weight of throwers group is relatively heavy. And so, the result of this study are similar to those of a study [27] which showed that sprinter or thrower groups are superior in muscular strength, muscular endurance, agility and speed ability than long -distance runners group. College sprinter athletes showed relatively high $\mathrm{VO}_{2} \mathrm{max}$, flexibility, mean power, and peak power[29].

Muscular strength is the sum of the forces that a muscle can exert during a single contraction [14]. And Muscular endurance is the ability of a muscle to sustain and repeat long period contractions and relaxations over a long time [15].

There were no significant differences in muscular endurance, flexibility, and agility in this study. Maybe, this is because South Korean national track and field athletes were at their best physical ability. It may also be a temporary episode in which the sample size is small.

In the Study on the Correlation Analysis between Physical Fitness and Athletic Performance for Elementary School Athletes, there was no correlation between sprinter and middle-long distance runners in muscular strength [20].

In a study on sports and body types, it was reported that not only are there body shapes suitable for the sport but also there is a difference in body shape between the athletes with and without superb athletic performance [30, 31]. Regarding the relationship between physical fitness factors 
and athletic performance specific fitness factors highly affected athletic performance in each athletic group, power and muscular endurance for the sprinter group, muscular endurance and cardiovascular endurance in middle distance runners group, muscular strength, agility, power and balance in jumper group, and muscular strength, agility and power in thrower group, highly affected athletic performance [32].

The correlations between performance and physical fitness are as follows: Korean high school sprinters were highly correlated with power and muscle endurance. The middle distance runners were highly correlated with muscular endurance and cardiopulmonary endurance. The jumpers were highly correlated with strength, agility, power and equilibrium. Throwers were highly correlated with exercise performance in strength, agility and power [8].

As the physique and physical strength factors required by each athlete groups differ, athletes with the appropriate physique and physical fitness conditions can exhibit good performance according to the characteristics of the sports.

Flexibility exercises have relieved amenorrhea and tension in the nerve roots and have been successfully prescribed for back pain [21]. For athletes, increased flexibility can reduce the risk of muscle injury. There was no significant difference in flexibility among the athlete groups in this study. The reason for this is that national representative athletes typically have adequate flexibility training.

There was no significant different in agility among the four track and field athlete groups in this study. Therefore, agility does not seem to represent a specific group of track and field athlete groups. This may be because national athletes have a common, well-developed agility.

In this study, the sprinter group had significantly stronger leg power (vertical jump) than the other three athlete groups. This is because the leg power of the sprinter plays an important role in the running power speed in athletics. If upper body power is compared, it is likely that the throwers have greater power.

The following is a review of cardiopulmonary endurance.

The predictive value of the marathon's future-oriented record was 1 hour 57 minutes 58 seconds. The basis of this estimation is based on the maximum oxygen uptake of $84 \mathrm{ml} / \mathrm{kg} / \mathrm{min}$ and the lactate threshold of $90 \%$ [18]. The most comprehensive analysis of marathon runners is maximal oxygen uptake, anaerobic threshold, and running efficiency [17]. Most marathon runners run at $75-85 \%$ of their maximum oxygen uptake and run at $86-90 \%$ of their maximum oxygen intake for some athletes approaching world record levels [16]. In this study, the marathon group was significantly higher in aspects of cardiopulmonary endurance than the jumper group or the thrower group. The maximal oxygen uptake level of the Korean national marathon athlete group was $72.6 \mathrm{ml} / \mathrm{kg} / \mathrm{min}$, which was $56 \mathrm{ml} / \mathrm{kg} / \mathrm{min}$ for the jumping group and $50.3 \mathrm{ml} / \mathrm{kg} / \mathrm{min}$ for the throwing group.
This is probably due to the higher cardiopulmonary endurance characteristics of the long-distance runners group compared to throwing or jumping athletes. The cardiovascular endurance of the long-distance runners is $30 \%$, and muscle strength is $25 \%$, muscle endurance is $15 \%$ and flexibility is $5 \%$ [11].

In a comparative study of the aerobic performance $\left(\mathrm{VO}_{2}\right.$ max) of Korean male marathoners and Kenyan male marathoners [4], Korean marathon runners were $74.1 \mathrm{ml} / \mathrm{kg} / \mathrm{min}$ and Kenyan marathon runners were $80.4 \mathrm{ml} / \mathrm{kg} / \mathrm{min}$. The maximal oxygen uptake and AT levels in the marathon athlete group were significantly higher in this study. The higher the AT level, the slower the onset of fatigue and the better the ability to sustain the exercise at high intensity [10]. Therefore, it was confirmed that the cardiovascular endurance of the national long-distance runners showed a relative superiority to other groups.

In this study, the South Korean national long-distance runner group was superior to the other three groups in cardiovascular endurance. The sprinter group was superior to the other three groups in power and the thrower group was superior to the other three groups in muscular power.

Just as the required training method, exercise amount, and technique are different according to the sports events, fitness required for each specific sports events also should be handled differently [28]. Although the number of sample size is small and has limitations in interpretation, the result of this study show similar tendency to those of the previous studies. If any of the physique or physical strength does not reach a superb level, it is difficult to succeed as an elite player [27]. Therefore, in order to become a solid player, proper body composition, physical condition and excellent professional fitness level are required for competitiveness as a global athlete. Generally, the jumper group was taller than other athlete (the long-distance runners group, the sprinter group) in height [29].

In conclusion, in this study, the jumper and sprinter group were taller than long-distance runners group, and the thrower group was the heaviest among the three groups. There was no significant difference in muscular endurance, flexibility, agility, and resting heart rate among the specific sports events. Power was the best in sprinters groups, and cardiovascular endurance was better in long distance runners group than in the jumper and thrower group. $\mathrm{AT} \% \mathrm{VO}_{2}$ max has the best in long-distance runners group. As such, Korean track and field national athletes have the appropriate physique and physical characteristics required for each sport. However, in order to have competitiveness as the global players, it is necessary to strengthen the professional physical strength and technical ability by applying training programs suitable for each sports event. The programs should reflect the main physical characteristics of each event.

\section{Conclusions}

The aim of this study was to compare physique and 
physical fitness among Track and Field athlete groups. The participating male athletes in this study consisted only of South Korean national track and field athletes. South Korean national athletes $(\mathrm{n}=24)$ were divided into four groups (long-distance runner $=7$, sprinter $=7$, jumper $=7$, thrower=4). Physique was limited to 2 items (height and weight). Physical fitness was limited to 6 items (muscular strength, muscular endurance, flexibility, agility, power, cardiopulmonary endurance). The details on physical fitness was divided into 9 fitness items (grip strength, pushups, sit ups, sit and reach, side step, vertical jump, maximal oxygen uptake, $\mathrm{ATVO}_{2}$ max, resting heart rate). The results are as follows.

The thrower group showed significantly better results in weight and muscular strength (grip strength) than the sprinter group, long-distance runner group and the jumper group. The long-distance runner group showed significantly better results in $\mathrm{VO}_{2} \max$ and $\mathrm{AT} \% \mathrm{VO}_{2}$ max than the other three groups (sprinter, thrower, jumper). The sprinter group showed significantly better results in power (vertical jump) than the other three groups. There was no significant difference between the groups in the results for muscular endurance (push-up, sit-up), flexibility (sit and reach), agility (side steps/20 seconds) and exercise endurance time.

In conclusion, South Korean national long-distance runner groups $\left(\mathrm{VO}_{2}\right.$ max: $72.6 \mathrm{ml} / \mathrm{kg} / \mathrm{min}, \quad \mathrm{AT} \% \mathrm{VO}_{2} \max$ : 75.5) were superior to the other two groups (jumper and thrower group) in cardiovascular endurance. Long-distance runners group (vertical jump: $40.6 \mathrm{~cm}$ ) were not superior to the other three groups in power. Moreover, the thrower group (weight: $108.5 \mathrm{~kg}$, grip strength: $78 \mathrm{~kg}$ ) was superior to the other three groups in muscular strength and was the heaviest of all groups. Therefore, athletes should be trained by constituting fitness programs according to the fitness factors required for each sports event, and by considering the importance of each factors in sports performance. Future studies should include a comparative study with larger sample sizes for each category of the athletic field.

\section{REFERENCES}

[1] Kim, M.H., Choi, M.D., Lee, M.M and Park, S.H. (2000). Relation of physique and physical fitness to athlete performance in track and field athlete's boy's high school. Journal of Physical Growth and Motor Development, 8(2)69-78.

[2] Macdougall, J. D. (1977). The anaerobic threshold its significance for the endurance athletes. Can. J. Appl. sports Science. 2. 137-140.

[3] Bouchard, C., Stephard, R. J., \& Stephens, T. (1994). Physical activity, fitness, and health, Champaign, IL: Human Kinetics.

[4] Cho, S. Y., Oh, C. S., \& Lee, J. H. (2012). The recovery rate of heart rate and blood lactate after maximal exercise test in
Korean and Kenyan male elite marathon runners. The Korea journal of physical education, 2012, 51(1), 273-281.

[5] Zemper, E. D. (2005). Track \& field injuries. Medicine and Sport Science, 48, 138-151.

[6] Malia, R.M., Happer, A.B., Avent,H.H., \& Campbell, D.E.(1971). Physique of female and athletes. Med, Sci, Sports, 3, 32-38.

[7] Olds, T.S., \& Kang, S.J. (2000). Anthropometric characteristics of adult male Korean Taekwondo players. Proceedings of the 1st Olympic Taekwondo Scientific Congress, 69-75.

[8] Kim, M. H., Choi, M.D., Lee, Y. M., \& Park, S. H. (2000). Relation of physique and physical fitness to athletic performance in track and field athlete's boys high school. Journal of Physical Growth and Motor Development, 8(2), 69-78.

[9] SUNG, Bonju. (2006). World-class track and field athletes prefer physical fitness rather than physique. Journal of Sport Science, Korea Institute of Sport Science. 97, 40-47.

[10] Im, K.C. Lee, C.J., \& Rho, D.J. (2011). Composition of cardiopulmonary function, physical fitness and oxidative stress between among female college student. Journal of coach development, 13(1), 205-214.

[11] Korea Institute of Sport Science (1998). Development of computerized management system for diagnosis and evaluation of excellent athletes.

[12] SUNG, B. J., PARK, M.S., YOO, D.S., CHUNG, B.C. (2014). Compairing research of $100 \mathrm{~m}$ players on stride step, stride length, stride mean velocity, stride frequency and reaction time in the international and KOR. National Championship sprinter final. The Korea Journal of Sport, 12(1), 195-206.

[13] SUNG, B. J., \& Lee, Y. S. (2011). An Examination of basic and specific fitness of elite national throwing athletes (javelin, shot put, discus, hammer throwers). 22(3). 2220-2236.

[14] Thorstensson, A., Larsson, L., Tesch, P., \& Karlsson, J. (1977). Muscle strength and fiber composition in athletes and sedentary men. Medicine and Science in Sports. 9(1), 26-30.

[15] Bell, G. J., \& Wenger, H.A. (1992). Physiological adaptation to velocity-controlled resistance training, Sports Medicine, 13(4), 234-44.

[16] Costill, D. L. (1981). Scientific approach to distance running Track \& Field News.

[17] Wells G. D., Norris S. R. (2009). Assessment of physiological capacities of elite athletes \& respiratory limitations to exercise performance. Paediatric Respir. Rev.; 10:91-8.

[18] Joyner MJ (1991). Modeling: optimal marathon performance on the basis of physiological factors. J Appl. Physiol, 70: 683-7.

[19] Tolfrey K, Hansen SA, Dutton K, McKee T, Jones AM. (2009). Physiological correlates of 2-mile run performance as determined using a novel on-demand treadmill. Appl. Physiol Nutr Metab 34:763-72.

[20] Kim, Y.K. (1997). A study on correlation of physique, 
physical fitness, and record of elementary school athletes. Graduate school Kong Ju National Univ.

[21] Kraus, H. and Raab, W. (1961). Hypokinetic Disease. Springfield, IL: Charles C. Thomas.

[22] Hamiltonm, N.(1994). Changes in sprint stride kinematics with age in master's athletes. Int. J. Sports Biomech, 9, $15-26$.

[23] Korchmny, R. (1994). Speed development training menu. Track Technique, 129, 4105-4110.

[24] Boucahard, C., \& Malina, R. M. (1983). Genetics of physiological fitness and motor performance. Exerc. Sport Sci. Rev., 11, 306-309.

[25] Astrand, P.O., Rodahl, K. (1986).Textbook of work physiological bases of exercise. New York: McGraw-Hill.

[26] Katch, V., Waltman, A., Sady, S., \& Freedson, P. (1978). Validity of the relative percent concept for equating intensity. Eur. J. Appl. Physiol. Occup. Physiol., 389(4), 219-227.

[27] Hong, C. B., Ahn, N.Y., \& Kim, K.J. (2010). Differences between the events in age groups when physical fitness is evaluated for selecting excellent athletes. Journal of Coaching Development, 12(1), 213-224.
[28] Lee, K. W., Lee, D. K/.. \& J, Y. S. (1999). The Comparative Study of Leg Muscle Isokinetic Strength in Sprinter and Jumper in Athletics. Journal of the Korea Exercise Science Academy, 8(3), 361-372.

[29] Kim, K.H., \& Lim, K. I. (2017). Analysis of physical fitness and predicting performance in short distance runners: Elite vs Non-Elite Athletes. The Korea Journal of Sports Science. 26(2), 1173-1180.

[30] Carter, J.E.L., \& Ackland, T. R. (1994). Kinanthropometry in aquatic sports; A study of world Champaign, IL; Human Kinetics.

[31] Carter, J.E.L., \& Heath, B. H. (1990). Somatotyping development and applications. Cambridge: Cambridge University Press.

[32] Kim, M.H., Choi, J.D., Lee. M.M., \& Park, S. W. (2000). Relation of Physique and Physical Fitness to Athletic Performance in Track and Field Athlete`s Boy`s High School, 8(2), 69-78.

[33] Park. K.J., Lee. B.J., Lee. J. Y. \& Jung. C.M. (1982). A study on the desirable standard of physique for selecting the representative players. Seoul National Univ. Sport Science Lab. 725-823. 